\title{
MAPPING SuRfaCE CURRENTS IN MONTEREY BAY WITH CODAR-TYPE HF RADAR
}

\author{
By Jeffrey D. Paduan and Michael S. Cook
}

$\mathrm{H}$

IGH-FREQUENCY (HF) radar measurements have been employed around Monterey Bay, CA, to measure ocean surface currents since February 1992. The first array consisted of two older-generation CODAR instruments located at sites near Monterey in the south and Moss Landing, halfway around the bay to the north (Front Cover; Fig. 1). In 1994, the southern site was replaced with a newer-generation SeaSonde system at Pt. Pinos and a similar unit was installed near Santa Cruz on the northern shore of Monterey Bay. Finally, in 1996, the CODAR system in Moss Landing was replaced by a modern SeaSonde unit.

Several months time series of two-dimensional surface currents have been collected for Monterey Bay since the first CODAR units were installed. These data represent the most extensive measurements collected to date from compact, directionfinding HF radar systems (Barrick and Lipa, 1997; Paduan and Graber, 1997). Indeed, Monterey Bay is the only location where continuous HF radar measurements are underway. The geometry of the bay (a curving coastline with a radius of $\sim 20 \mathrm{~km}$ ) is ideal for a multisite HF radar network. The overwater distance is close to the typical radar range and, when three or more shore locations are utilized. the entire region can be observed without lost coverage along the baseline between radar sites.

This geometry also makes Monterey Bay well suited for validation and development of the algorithms for currents, waves, and wind direction because a large ocean region is oversampled. Not only can in situ measurements within this region be compared with the remotely sensed estimates, but self-consistency (or lack thereof) in the HF radar measurements can be used to characterize errors in the radar data (Melton, 1995).

Jeffrey D. Paduan and Michael S. Cook, Oceanography Department, Code OC/Pd, Naval Postgraduate School, Monterey, CA 93943. USA.

\section{Dominant Current Patterns}

Surface currents around Monterey Bay have strong modes of variability that are well separated in terms of the process timescales. At the longer timescales (weeks to months), the HF radar-derived currents show mesoscale patterns that evolve with major wind reversals and the proximity of mesoscale eddies (Paduan and Rosenfeld, 1996). At the shorter timescales, current fluctuations are dominated by semidiurnal tidal forcing and diurnal wind (seabreeze) forcing (Foster, 1993; Petruncio, 1993).

\section{Subtidal Current Patterns}

Paduan and Rosenfeld (1996) compared five month-long time series of radar-derived current with moored current observations at the Monterey Bay Aquarium Research Institute (MBARI) mooring site M1 (Fig. 1). Both time series were lowpass filtered to remove diurnal and shorter-period fluctuations revealing significant correlation dominated by reversals in the alongshore flow on timescales of a few weeks. These surface current reversals are related to the wind and to cross-shore movement of a warm-core eddy feature often observed near Monterey Bay.

A major advantage of $\mathrm{HF}$ radar measurements is their ability to describe these processes in two dimensions. Complicating this description, however, is the rapid response of the $\sim 1 \mathrm{~m}$ currents to changes in the wind. The agreement between radar-derived current and deeper flow, or between radar-derived current patterns and temperature patterns, can depend on the elapsed time since the last major wind shift.

An example of the subtidal-period surface current pattern during upwelling conditions is shown on the cover of this issue, together with satellitederived sea surface temperatures. Several recurring features of the summertime circulation are evident in that figure, including cyclonic flow within Monterey Bay, strong equatorward flow across the mouth of the Bay coincident with a plume of upwelled water originating from further north, and
.. the HF radar-

derived currents show

mesoscale patterns

that evolve with major

wind reversals and

the proximity of

mesoscale eddies. 


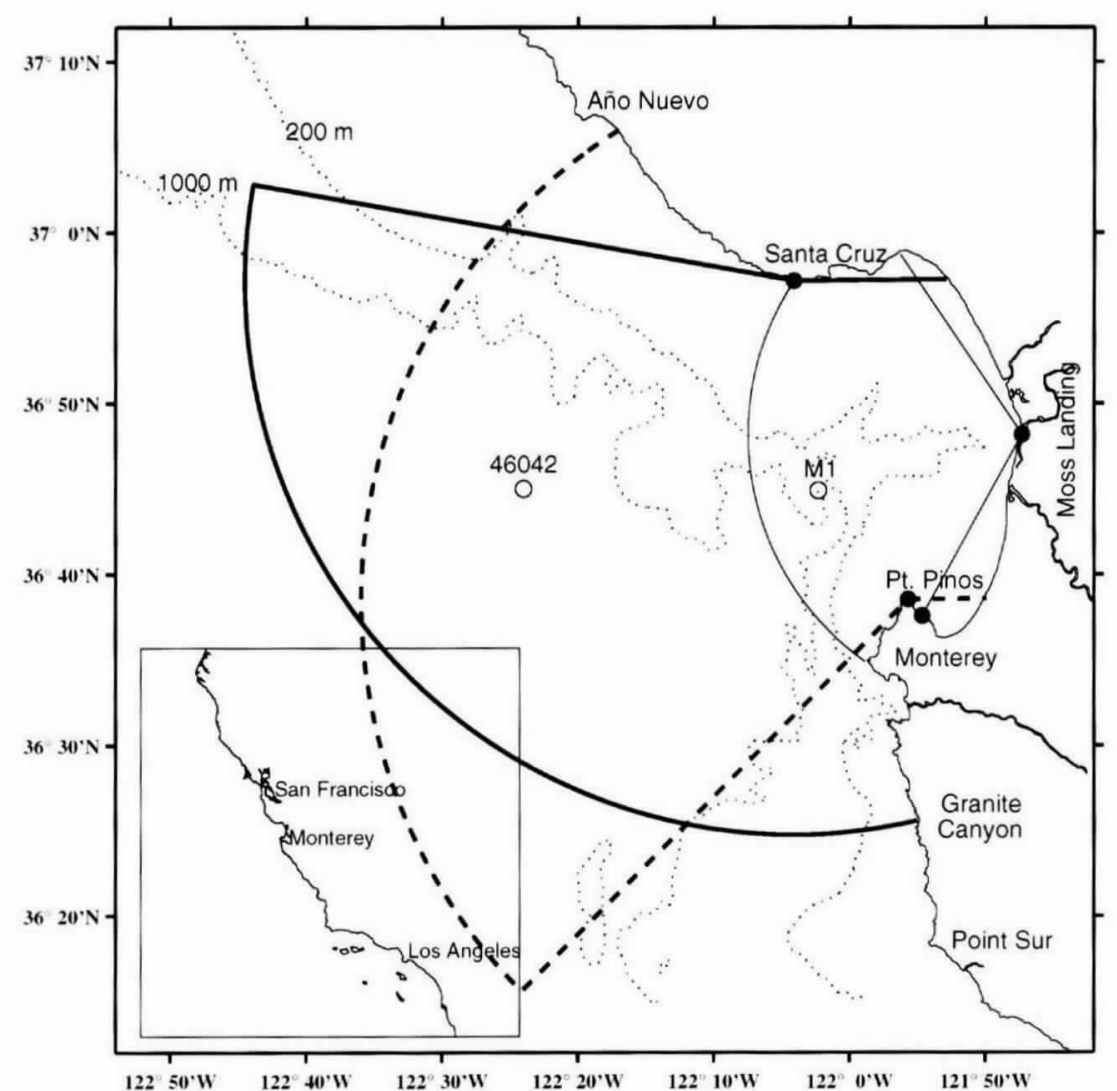

Fig. 1: Monterey Bay HF radar network showing nominal coverage areas for the 12.5 $\mathrm{MHz}$ antennae at Santa Cruz (-) and Pt. Pinos (--) and the $25.4 \mathrm{MHz}$ antenna at Moss Landing. MBARI (MI) and NOAA (46042) mooring locations are also shown (O).

$R_{\text {adar-derived sur- }}$

face currents from

this day show strong, smoothly varying equatorward flow. . . anticyclonic flow offshore associated with a warmcore mesoscale feature (Rosenfeld et al., 1994).

An example of the time variable nature of the subtidal current patterns can be seen later in the five month-long record from 1994. Winds measured at the offshore National Oceanic and Atmospheric Administration (NOAA) buoy 46042 and at the M1 mooring are shown in Figure 2 for a 3wk period in the Fall. The records show upwelling-favorable, equatorward winds interrupted by periods of poleward wind lasting 1-2 d. The M1 site also shows significant diurnal variability as discussed in the next section. The only clear satellite images available between 1-10 November 1994 are from 3 and 8 November at the times indicated on Figure 2. Daily averaged HF radar currents are shown together with these images on Figure 3.

Interpretation of the temperature-current comparisons in Figure 3 benefits from our knowledge of the wind history. The image from 3 November follows a long period of upwelling-favorable winds. A broad band of cold water is seen along the coast and across the mouth of Monterey Bay. Radar-derived surface currents from this day show strong, smoothly varying equatorward flow that follows an anticyclonic arc around the warm feature at the offshore side of the region.
After rapid wind reversal on 4 November, radar-derived current patterns (not shown) quickly develop regions of poleward flow and a lot of submesoscale $(\sim 10 \mathrm{~km})$ structure. The poleward flow develops first along the coast. The response timescale of the temperature field after a wind reversal is longer than that of the $\sim 1 \mathrm{~m}$ velocity field. For this example, daily averaged currents at the end of the poleward wind event on 6 November (Fig. 2) show better correlation with the features in the temperature field of 8 November than do contemporaneous currents. The comparison on Figure 3 shows how cold water flooding into Monterey Bay from the south changed the surface temperatures in the Bay between 3 November and 8 November.

\section{Semidiurnal Tidal Currents}

In addition to the subtidal-period motions, surface currents around Monterey Bay exhibit strong fluctuations with periods in the tidal bands. The ability to map these fluctuations using HF radar has led to a clearer understanding of the source of these motions. For example, the spatial patterns differ markedly for motions with semidiurnal and diurnal periods. The semidiurnal-period motions are largely due to forcing by the dominant M2 (12.4 h) tidal constituent. Diurnal motions, on the other hand, are largely explained by fluctuations of the wind at, approximately, diurnal $(\sim 24 \mathrm{~h})$ periods.

Evidence for tidal forcing of semidiurnal currents can be seen in Figure 4, which presents tidal ellipses resulting from harmonic analyses (e.g., Godin, 1972) of the currents at each radar grid point for the month of August 1994. For the semidiurnal (M2) currents, there is a clear relationship between the ellipse size and orientation and the bathymetry of the Monterey Submarine Canyon. Ellipses are largest over the head of the canyon near Moss Landing and the orientations of their major axes tend to align with topography on either side of the canyon axis. This structure was first seen in two-site CODAR data from 1992 (Petruncio, 1993). In addition to the correlation with topography, the phases of the M2 currents are such that water flows out of Monterey Bay at the surface during times of rising sea level. This relationship is counter to that expected for barotropic currents successively filling and emptying the bay each tidal cycle. Clearly, the observed M2 currents are surface manifestations of internal (baroclinic) tidal motions driven by the interaction of sea level oscillations and depth changes along the continental margin. Petruncio et al. (1997) describe field measurements that confirm that large amplitude internal waves of semidiurnal period fill the lower few hundred meters of the Monterey Submarine Canyon. This also explains why, at the surface, the semidiurnal current oscillations associated with these waves are strong where the energy intersects the surface (near the coast and far offshore) and 


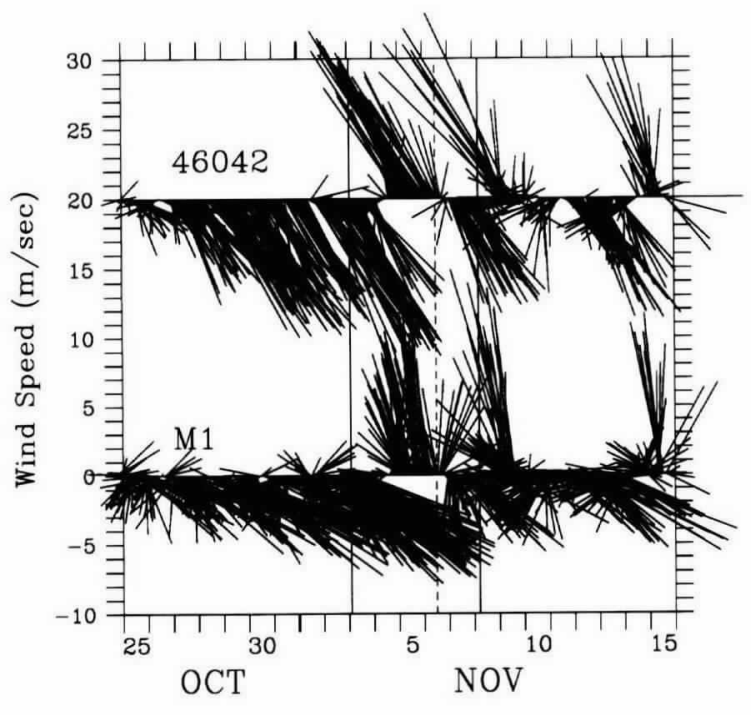

Fig. 2: Wind velocity from NOAA buoy 46042 and MBARI mooring M1 in 1994. Vertical lines denote times of satellite temperature images and $H F$ radar currents in Figure 3. Current measurements on the later image are centered $41 \mathrm{~h}$ before the image (---).

weak directly over the deep generation region (near the mouth of Monterey Bay).

\section{Diurnal Wind Driven Currents}

In stark contrast to the pattern of current oscillations with semidiurnal periods, the diurnal-period surface currents exhibit fairly uniform motions. The K1 (23.9 h) "tidal" ellipses in Figure 4 show large $\left(\sim 20 \mathrm{~cm} \mathrm{~s}^{-1}\right)$ oscillations with major axes aligned, primarily, in the northwest-southeast direction. This direction mimics that of the Salinas Valley, which is open to the sea near Moss Landing. Relatively strong heating inland drives a seabreeze flow most afternoons that is strongest at the coast, but still substantial over the ocean at the M1 mooring site and, to a lesser degree, at NOAA buoy 46042 . The $\mathrm{K} 1$ wind oscillations at these offshore sites during August 1994 are also shown on Figure 4.

The seabreeze cycle in the winds is a broadband process centered near the diurnal period. Harmonic analyses of coastal surface currents at periods close to the diurnal period are dominated by this wind forcing. Other important observations from the K1 ellipses in Figure 4 that deserve further study include the following: 1) the apparent clockwise rotation of the surface $\mathrm{K} 1$ currents relative to the wind (this $\sim 45^{\circ}$ rotation is in keeping with the Ekman theory, but steady-state Ekman balance is not required for these rapidly changing currents); 2) the rapid decay with depth of the diurnal motions at the M1 mooring site (this is in keeping with the downward transfer of momentum from wind to currents; the amplitude at $10 \mathrm{~m}$ on the mooring is 5 times less than the amplitude at $\sim 1 \mathrm{~m}$ ); and 3 ) the reduction of $\mathrm{K} 1$ oscillations
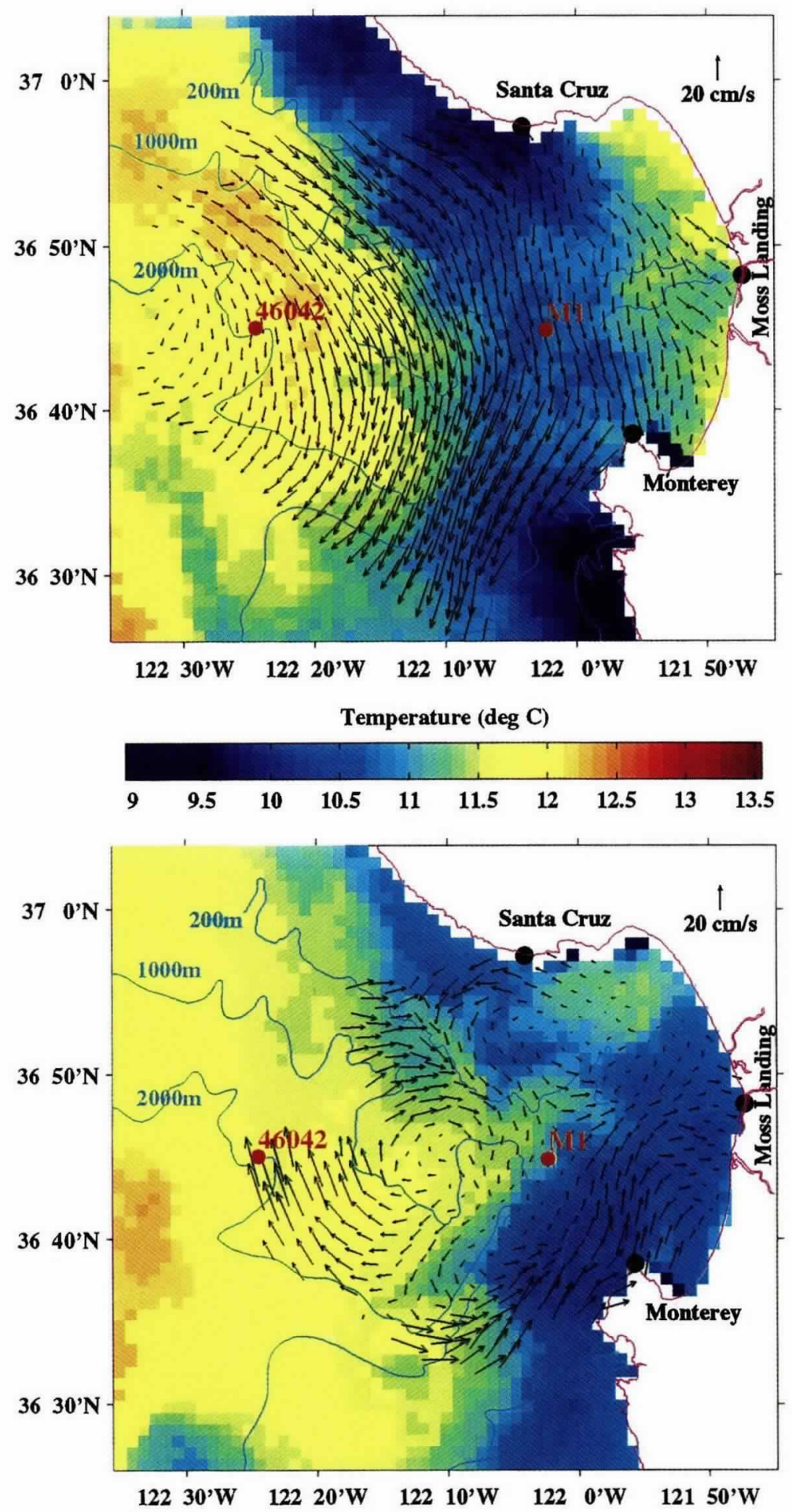

Fig. 3: Uncorrected sea surface temperatures from AVHRR for 0200 GMT, 3 November 1994 (top) and 0500 GMT, 8 November 1994 (bottom) with daily averaged, radar-derived surface currents centered on the image time (top) and $41 \mathrm{~h}$ before the image (bottom). Locations of the coastal radar sites and the offshore MBARI mooring M1 and NOAA buoy 46042 are also shown (•).

near the coast (this is in keeping with the expectation that currents will be inhibited by the boundary at some point as the coast is approached).

Looking again at the M2 tidal ellipses, we note that the M2 currents at $10-\mathrm{m}$ depth at the mooring site are of comparable magnitude to those mea- 


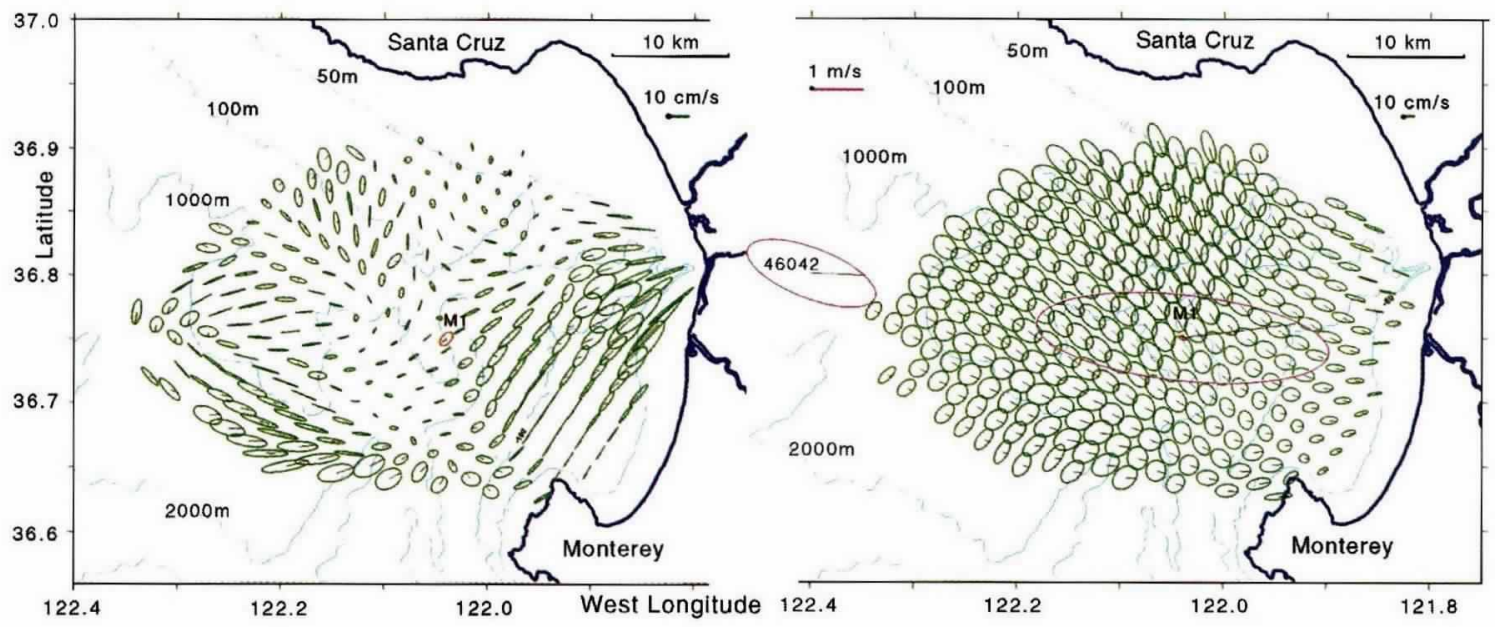

Fig. 4: Tidal ellipses at M2 (12.4 h; left) and $\mathrm{Kl}(23.9 \mathrm{~h}$; right) periods from HF radar currents at $\sim 1 \mathrm{~m}$ (green), $A D C P$ currents at $10 \mathrm{~m}$ at the M1 mooring (red), and wind at the M1 mooring and NOAA buoy 46042 (magenta) for the month of August 1994. Lines emanating from the center of the ellipses denote the flow direction at the time of high coastal sea level for each constituent.

\section{. . . low-pass-filtered}

current maps help to

describe the evolution

of coastal upwelling

filaments after reversals

of the along-coast

wind. sured at $\sim 1 \mathrm{~m}$ using HF radars. This is further evidence that diurnal oscillations observed by the radar network are accurate representations of a near-surface process related to wind forcing, whereas the semidiurnal oscillations have longer vertical scales and are related to the shape of the local bathymetry.

\section{Conclusions}

In summary, we have looked at several applications of direction-finding HF radar measurements to the study of coastal surface currents around Monterey Bay. Evidence pointing to the utility of these remotely sensed data is overwhelming. In no other (practical) way is it possible to obtain twodimensional current maps on hourly timescales for periods of months on end.

In our area, low-pass-filtered current maps help to describe the evolution of coastal upwelling filaments after reversals of the along-coast wind. This circulation is critical to the distribution of nutrients in the coastal zone, and to the transport of surface dwelling larvae (Bjorkstedt and Roughgarden, 1997). Surface currents respond more quickly to wind changes than do temperatures, a fact which points out the need to use HF radar data in a manner consistent with the very near-surface nature of the measurement (Chapman and Graber, 1997). At higher frequencies, the HF radar data clearly distinguish the effects of tidal and wind-driven forcing for semidiurnal- and diurnal-period motions, respectively.

Finally, we note that the Monterey Bay HF radar network provides an ideal natural laboratory for the study of these coastal processes. It is also ideally suited to investigation of the accuracy of algorithms applied to HF backscatter spectra, such as the new direction-finding technique described by Barrick and Lipa (1997).

\section{Acknowledgments}

We received helpful feedback from Leslie Rosenfeld, and we thank Michael Foreman for providing the harmonic analysis software and Emil Petruncio for helping us to apply it. Gerry Hatcher helped to produce the figures of radar currents and satellite temperatures. This work was supported by the ONR REINAS project and by ONR contract N0001495WR30022.

\section{References}

Barrick, D.E. and B.J. Lipa, 1997: Evolution of bearing determination in HF current mapping radars. Oceanography, 10, 72-75.

Bjorkstedt, E.P. and J. Roughgarden, 1997: Larval transport and coastal upwelling: an application of HF radar in ecological research. Oceanography, 10, 64-67.

Chapman, R.D. and H.C. Graber, 1997: Validation of HF radar measurement. Oceanography, 10, 76-79.

Foster, M.D., 1993: Evolution of diurnal surface winds and surface currents for Monterey Bay. M.S. thesis, Naval Postgraduate School, 100 pp.

Godin, G., 1972: The Analysis of Tides. Univ. of Toronto Press, Toronto.

Melton, D.C., 1995: Remote sensing and validation of surface currents from HF radar. M.S. thesis, Naval Postgraduate School, 66 pp.

Paduan, J.D. and H.C. Graber, 1997: Introduction to high-frequency radar: reality and myth. Oceanography, 10, $36-39$.

- and L.K. Rosenfeld, 1996: Remotely sensed surface currents in Monterey Bay from shore-based HF radar (CODAR). J. Geophys. Res., 101, 20669-20686.

Petruncio, E.T., 1993: Characterization of tidal currents in Monterey Bay from remote and in-situ measurements. M.S. thesis, Naval Postgraduate School, 113 pp.

, L.K. Rosenfeld and J.D. Paduan, 1997: Observations of the internal tide in Monterey Submarine Canyon. $J$. Phys. Oceanography. In press.

Rosenfeld, L.K., F.B. Schwing, N. Garfield and D.E. Tracy, 1994: Bifurcated flow from an upwelling center: a cold water source for Monterey Bay. Cont. Shelf Res., 14. 931-964. $\square$ 